\title{
Damage assessment of the longitudinal connection of simple supported-to-continuous girder bridges constructed with hollow slabs
}

\author{
Jin $\mathrm{Liu}^{12, \mathrm{a}^{*}}$, Jinquan Zhang ${ }^{2, \mathrm{~b}}$, Wanheng $\mathrm{Li}^{2, \mathrm{c}}$, and Bo Diao ${ }^{1, \mathrm{~d}}$ \\ ${ }^{1}$ School of Transportation Science and Engineering, Beihang University, Beijing 100191, China \\ ${ }^{2}$ Research Institute of Highway, MOT, Beijing 100088, China \\ aliu.jing@rioh.cn, bjq.zhang@rioh.cn, cwh.li@rioh.cn, ddiaobo@buaa.edu.cn
}

Keywords: longitudinal connection, simple supported-to-continuous girder bridges, numerical study, cracks, hollow slab

Abstract Simple supported-to-continuous girder bridges are commonly and widely used in bridge engineering in China. For this type of bridges, normally, the longitude connections are casted in-site by concrete. The quality of the casted concrete is difficult to control. After a large number of field surveys, damages are often found in the transversal and longitudinal connections. These damages may result in unfavorable effects to the bridge system and shorten the durability of the bridges. Therefore it is of great interests to investigate the behavior of the concoctions on this kind of bridges. This paper presents a numerical study of the longitudinal connections of simple supported-to-continuous girder bridges. Then by series parametric study, the effect of the damages on the connections on the mechanical behavior of the bridge is investigated.

\section{Introduction}

For the reasons of easily construction and economic, simple supported-to-continuous girder bridges are commonly and widely used in bridge engineering in China. For this type of bridges, normally, the longitude connections are casted in-site by concrete. The quality of the casted concrete is difficult to control [1-4]. After a large number of field surveys, damages are often found in the transversal and longitudinal connections. These damages may result in unfavorable effects to the bridge system and shorten the durability of the bridges [5]. Therefore it is of great interests to investigate the behavior of the concoctions on this kind of bridges. Now, only a few qualitative methods for the assessment of the longitudinal connection are available in JTG/T H21-2011 and JTG/T J21-2011 [6-8]. This study presents a numerical study on the effect of strength reduction of the connections on the performance of the bridges. Based on the results, a damage assessment method is proposed for the longitudinal connection of simple supported-to-continuous girder bridges.

\section{Numerical modeling parameters}

In this section, the numerical modeling parameters will be presented first. The numerical calculation model is based on the Chinese standard manual for hollow section slab bridge, in which a prototype of a $16 \mathrm{~m}$ with 5 spans is selected as the example, see Fig. 1. M1 M3、d1 d3 are bending moment and deflection in the middle of the spans, respectively.

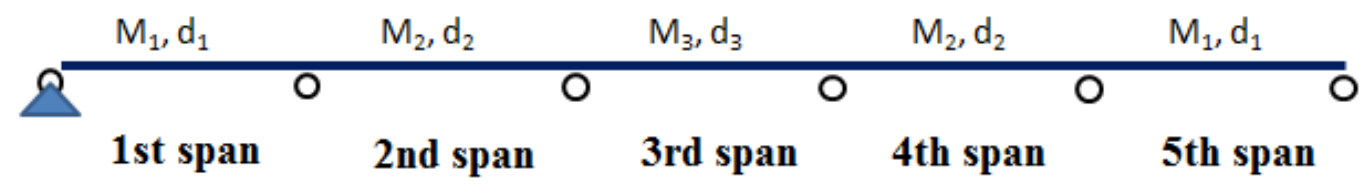

Figure 1, Calculation model of a simple supported-to-continuous girder bridge

The load applied on the calculation model is based on the Chinese standard (JTG D60-2004). The internal forces are calculation as a class structural member. The load applied on slab is re-calculated using a load transfer factor. The connection of the slab and concrete girder is regarded as stiff moment 
connection. The numerical calculation is carried out by FEM method using truss or beam element. The damage of the longitude connection is considered by strength reduction of the concrete.

\section{Effect of damage at longitudinal connection on the performance of bridge}

\section{Influence on the side span $\left(1^{\text {st }}\right.$ and $5^{\text {th }}$ span $)$}

With different bending stiffness (damages are introduced) of the connection, under only live load, the maximum bending moment is summarized in Table. 1; under live load + dead load, the maximum bending moment is summarized in Table. 2. For the convenience of analysis, the values in Tables 1 and 2 are normalized as of $\mathrm{D}_{\mathrm{EI}}$ (damage factor) and $\mu_{\mathrm{M}}$. $\mathrm{D}_{\mathrm{EI}}=1-(\mathrm{EI}) /\left(\mathrm{E}_{0} \mathrm{I}_{0}\right) ; \mu_{\mathrm{M}}=\mathrm{M} /\left(\mathrm{M}_{0}\right) .\left(\mathrm{E}_{0} \mathrm{I}_{0}\right)$ and $\mathrm{M}_{0}$ are the inital stiffness and bending moment when there is no damages, see Fig. 2.

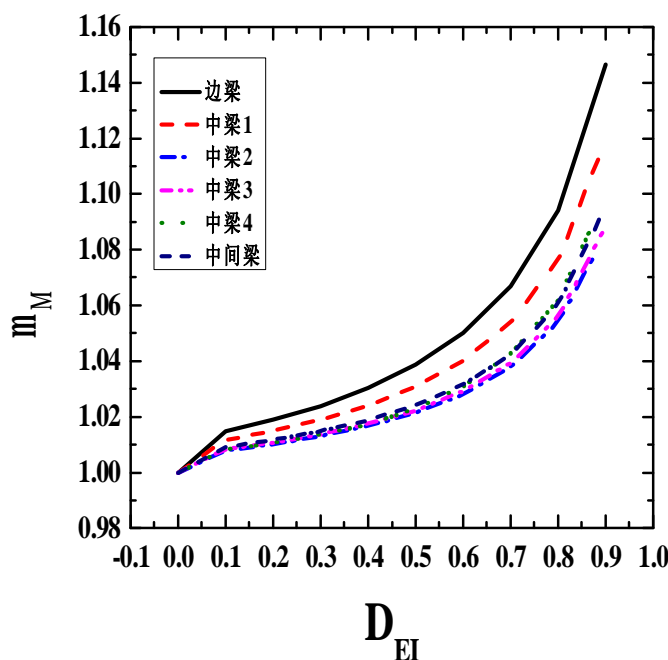

(a) Live load

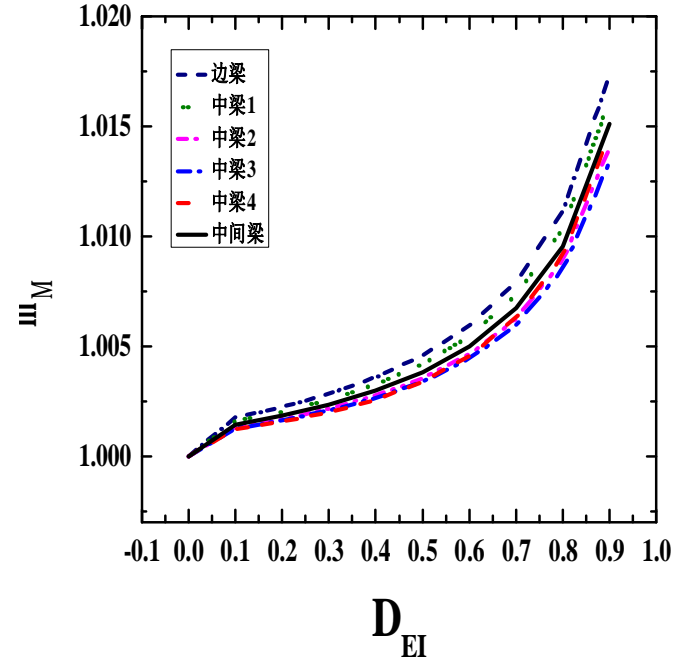

(b) live load + dead load

Figure 2. The trend of damage of $1^{\text {st }}$ and $5^{\text {th }}$ span

From Tables 1 and 2 and Fig. 2, it can be seen that (1) for case a and b, the maximum bending moment increases with the increase of damage factor. This indicates that for a bridge system, the bending stiffness of on span will influence the bending moment of all spans. (2) When only the live load is considered, the influence of damage on the bending moments of each span is different, the side span 1 and 5 are more influenced. When $\mathrm{D}_{\mathrm{EI}}<0.4$, the increase of bending moment are not important, less than 3\%; when $\mathrm{D}_{\mathrm{EI}}>0.6$, the influence is important, more than $5 \%$. When $\mathrm{D}_{\mathrm{EI}}=0.9$, the increase of the bending moment reaches the maximum $14.6 \%$. For the other spans, when $\mathrm{D}_{\mathrm{EI}}<0.5$, increasing of bending moment is less than $5 \%$. When $\mathrm{D}_{\mathrm{El}}=0.9$, the maximum increment is $9.9 \%$. (3) When the live load and dead load are considered together, the influcence could be ignored, less than $1.6 \%$.

\begin{tabular}{|c|c|c|c|c|c|c|c|c|c|c|}
\hline \multirow{2}{*}{ No } & \multicolumn{10}{|c|}{ DEI $=1-(E I) /\left(E_{0} \mathbf{I}_{0}\right)$} \\
\hline & $\mathbf{0}$ & 0.1 & 0.2 & 0.3 & 0.4 & 0.5 & 0.6 & 0.7 & 0.8 & 0.9 \\
\hline side span & 391.31 & 397.14 & 398.72 & 400.68 & 403.17 & 406.43 & 410.93 & 417.52 & 428.16 & 448.63 \\
\hline span 1 & 342.83 & 346.85 & 347.96 & 349.33 & 351.09 & 353.40 & 356.59 & 361.31 & 368.94 & 383.75 \\
\hline $\operatorname{span} 2$ & 438.61 & 442.09 & 443.10 & 444.35 & 445.94 & 448.03 & 450.94 & 455.24 & 462.27 & 476.04 \\
\hline span 3 & 402.88 & 406.25 & 407.22 & 408.39 & 409.91 & 411.89 & 414.65 & 418.73 & 425.40 & 438.49 \\
\hline span 4 & 393.96 & 397.25 & 398.17 & 399.31 & 400.75 & 403.00 & 406.14 & 410.76 & 418.32 & 433.15 \\
\hline $\begin{array}{l}\text { Middel } \\
\text { span }\end{array}$ & 428.97 & 432.89 & 434.00 & 435.34 & 437.08 & 439.35 & 442.51 & 447.19 & 454.85 & 469.90 \\
\hline
\end{tabular}

Table 1 Beindg moment with live load $\left(\mathrm{KN}^{*} \mathrm{~m}\right)$ 


\begin{tabular}{|c|c|c|c|c|c|c|c|c|c|c|}
\hline \multirow{2}{*}{ No } & \multicolumn{10}{|c|}{ DEI $=1-(E I) /\left(\mathbf{E}_{0} \mathbf{I}_{0}\right)$} \\
\hline & 0.0 & 0.1 & 0.2 & 0.3 & 0.4 & 0.5 & 0.6 & 0.7 & 0.8 & 0.9 \\
\hline side span & 3305.66 & 3311.49 & 3313.07 & 3315.03 & 3317.52 & 3320.78 & 3325.28 & 3331.87 & 3342.51 & 3362.98 \\
\hline span 1 & 2524.94 & 2528.96 & 2530.07 & 2531.44 & 2533.2 & 2535.51 & 2538.7 & 2543.42 & 2551.05 & 2565.86 \\
\hline span 2 & 2660.81 & 2664.29 & 2665.3 & 2666.55 & 2668.14 & 2670.23 & 2673.14 & 2677.44 & 2684.47 & 2698.24 \\
\hline span 3 & 2655.48 & 2658.85 & 2659.82 & 2660.99 & 2662.51 & 2664.49 & 2667.25 & 2671.33 & 2678 & 2691.09 \\
\hline span 4 & 2666.79 & 2670.08 & 2671 & 2672.14 & 2673.58 & 2675.83 & 2678.97 & 2683.59 & 2691.15 & 2705.98 \\
\hline Middel span & 2711.38 & 2715.3 & 2716.41 & 2717.75 & 2719.49 & 2721.76 & 2724.92 & 2729.6 & 2737.26 & 2752.31 \\
\hline
\end{tabular}

Table 2 Beindg moment with live load + dead load $\left(\mathrm{KN}^{*} \mathrm{~m}\right)$

\section{Influence on the middle-side span ( $2^{\text {nd }}$ and $4^{\text {th }}$ span)}

As it mentioned in the previous section, the same analysis method is adopted in this section. The results for live load and live load + dead load are summarized in Tables 3 and 4 . The normalized curves are shown in Fig. 3.

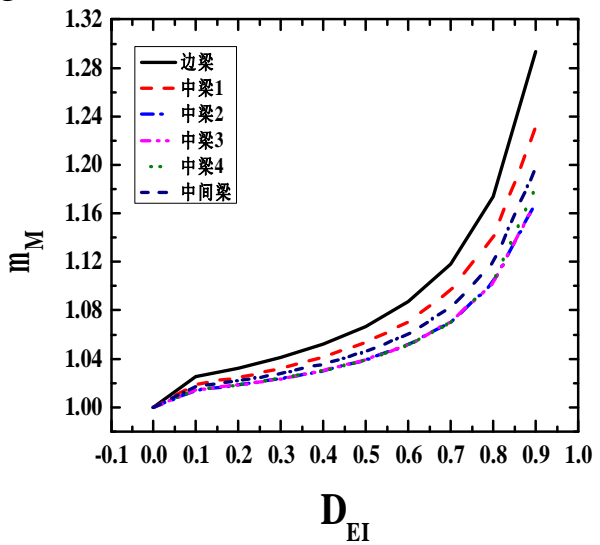

(a) Live load

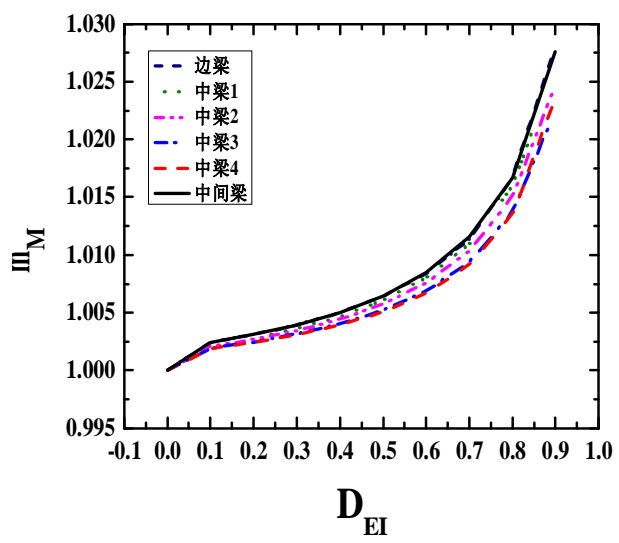

(b) live load + dead load

Figure 3. The trend of damage of $2^{\text {nd }}$ and $4^{\text {th }}$ span

From Tables 3 and 4 and Fig. 3, it can be seen that (1) for case a and b, the maximum bending moment increases with the increase of damage factor. This indicates that for a bridge system, the bending stiffness of on span will influence the bending moment of all spans. (2) When only the live load is considered, the influence of damage on the bending moments of each span is different, the side span 2 and 4 are more influenced. When $\mathrm{D}_{\mathrm{EI}}<0.2$, the increase of bending moment are not important, less than 3\%; when $\mathrm{D}_{\mathrm{EI}}>0.4$, the influence is important, more than $5 \%$. When $\mathrm{D}_{\mathrm{EI}}=0.9$, the increase of the bending moment reaches the maximum $29.4 \%$. For the other spans, when $\mathrm{D}_{\mathrm{EI}}<0.5$, increasing of bending moment is less than $5 \%$. When $\mathrm{D}_{\mathrm{EI}}=0.9$, the maximum increments are $23.1 \%, 16.95 \%$ 、 $16.96 \%, 18.2 \%$ and 19.7\%; (3) When the live load and dead load are considered together, the influcence could be ignored, less than $2.8 \%$.

\begin{tabular}{ccccccccccc}
\hline \multirow{2}{*}{ No } & \multicolumn{10}{c}{$\mathbf{D}_{\mathrm{EI}=\mathbf{1}-(\mathbf{E I}) /\left(\mathbf{E}_{\mathbf{0}} \mathbf{I}_{\mathbf{0}}\right)}$} \\
\cline { 2 - 12 } & $\mathbf{0}$ & $\mathbf{0 . 1}$ & $\mathbf{0 . 2}$ & $\mathbf{0 . 3}$ & $\mathbf{0 . 4}$ & $\mathbf{0 . 5}$ & $\mathbf{0 . 6}$ & $\mathbf{0 . 7}$ & $\mathbf{0 . 8}$ & $\mathbf{0 . 9}$ \\
\hline side span & 309.41 & 317.23 & 319.38 & 322.06 & 325.50 & 330.06 & 336.45 & 346.02 & 363.26 & 400.25 \\
\hline span 1 & 279.33 & 284.68 & 286.24 & 288.26 & 290.84 & 294.28 & 299.10 & 306.36 & 318.57 & 343.78 \\
\hline span 2 & 381.63 & 387.04 & 388.63 & 390.60 & 393.15 & 396.55 & 401.34 & 408.58 & 420.80 & 446.29 \\
\hline span 3 & 346.16 & 351.13 & 352.56 & 354.35 & 356.66 & 359.73 & 364.06 & 370.62 & 381.71 & 404.88 \\
\hline span 4 & 340.03 & 344.96 & 346.35 & 348.08 & 350.32 & 353.30 & 357.50 & 363.87 & 375.35 & 401.90 \\
\hline Middle span & 371.28 & 377.66 & 379.46 & 381.68 & 384.55 & 388.37 & 393.75 & 401.90 & 415.67 & 444.53 \\
\hline
\end{tabular}

Table 3 Beindg moment with live load (KN*m) 


\begin{tabular}{ccccccccccc}
\hline \multirow{2}{*}{ No } & \multicolumn{10}{c}{$\mathbf{D}_{\mathrm{EI}=\mathbf{1}-(\mathbf{E I}) /\left(\mathbf{E}_{\mathbf{0}} \mathbf{I}_{\mathbf{0}}\right)}$} \\
\cline { 2 - 11 } & $\mathbf{0 . 0}$ & $\mathbf{0 . 1}$ & $\mathbf{0 . 2}$ & $\mathbf{0 . 3}$ & $\mathbf{0 . 4}$ & $\mathbf{0 . 5}$ & $\mathbf{0 . 6}$ & $\mathbf{0 . 7}$ & $\mathbf{0 . 8}$ & $\mathbf{0 . 9}$ \\
\hline Side span & 3223.76 & 3231.58 & 3233.73 & 3236.41 & 3239.85 & 3244.41 & 3250.8 & 3260.37 & 3277.61 & 3314.6 \\
\hline span 1 & 2461.44 & 2466.79 & 2468.35 & 2470.37 & 2472.95 & 2476.39 & 2481.21 & 2488.47 & 2500.68 & 2525.89 \\
\hline span 2 & 2603.83 & 2609.24 & 2610.83 & 2612.8 & 2615.35 & 2618.75 & 2623.54 & 2630.78 & 2643 & 2668.49 \\
\hline span 3 & 2598.76 & 2603.73 & 2605.16 & 2606.95 & 2609.26 & 2612.33 & 2616.66 & 2623.22 & 2634.31 & 2657.48 \\
\hline span 4 & 2612.86 & 2617.79 & 2619.18 & 2620.91 & 2623.15 & 2626.13 & 2630.33 & 2636.7 & 2648.18 & 2674.73 \\
\hline $\begin{array}{c}\text { Middle } \\
\text { span }\end{array}$ & 2653.69 & 2660.07 & 2661.87 & 2664.09 & 2666.96 & 2670.78 & 2676.16 & 2684.31 & 2698.08 & 2726.94 \\
\hline
\end{tabular}

Table 4 Beindg moment with live load + dead load $\left(\mathrm{KN}^{*} \mathrm{~m}\right)$

\section{Conclusions}

This paper presents a numerical parametric study on the effect of damages on the longitudinal connection of simple supported-to-continuous girder bridges constructed with hollow slabs. From the results it can be seen that, the longitudinal connection plays very important role in the mechanical behavior of the whole system of the bridge. The maximum bending moment increases with the increase of damage factor. This indicates that for a bridge system, the bending stiffness of on span will influence the bending moment of all spans. In the Engineering practice, this effect should be paid with more attention during construction and bridge management and routine maintenance .

\section{References}

[1] HU Boxue, YAN Donghuang, GUAN Guodong, and XIAO Yonggang. "Mechanical Analysis of Bridge-pavement Crack about Simple-support before Continuous Bridge Model by the Software of ANSYS [J]”. Central South Highway Engineering, Vol.31, No.2, 2006.

[2] WU Chengfu, WU Jun. "Experimentation Analysis of the Precast Prestressed Continuous Concrete Box Girder in Elastic Phase [J]”. Central South Highway Engineering, Vol.31, No.3, 2006.

[3] HU Tieming, HUANG Chengkui, CHEN Xiaofen, and LIANG Zhenyu. "Fatigue damage experiment for junction of wet-joint of bridges transforming from simply-supported into continuous beams [J]". China Civil Engineering Journal, Vol.43, No.10, 2010.

[4] WANG Wenwei, WU Wenqing, LI Shuqin, YANG Wei, and WENG Changnian. "Experimental Study and Calculation Method on Moment Redistribution Induced by Transforming Simply Supported Beams into Continuous Beams [J]”. Engineering Mechanics, Vol.27, No.5, 2010.

[5] WANG Weiwei, LI Shuqin, and WENG Changnian. "An Experimental Study on Transform of Old Simply Supported Beams into Contiuous Beams [J]". China Civil Engineering Journal, Vol.42, No.6, 2009.

[6] YAO Guowen, SONG Wenfeng. "Analysis on Typical Disease and Its Mechanism of Simply-supported T-shaped Beam Bridge with Continuous Slab-decks [J]". Journal of Chongqing Institute of Technology (Natural Science Edition), Vol.21, No.12, 2007.

[7] SHENG Xingwang, ZHOU Xianghua. "Fatigue Behavior and Anticrack Property of Simply Supported-to-Continuous Beam [J]”. Journal of Central South University, Vol.36, No.3, 2005.

[8] LIU Bo, SHENG Xingwang. "Test Study of the Static and Dynamic Property on Prestressed Concrete Beam Construction by Converting Simple Support into Continuous Support [J]'. China Railway Science, Vol.25, No.6, 2004. 